\title{
Awareness and Community Response To Stroke Signs and Symptoms Following the National 'Act Fast' Campaign in An Ethnically Diverse Population
}

\section{Zain A. Bhutta ( $\sim$ zain.bhutta@helsinki.fi )}

Helsinki University Hospital and University of Helsinki

\section{Sameer A. Pathan}

Hamad Medical Corporation

\section{Tuukka Puolakka}

Helsinki University Hospital and University of Helsinki

Naveed Akhtar

Hamad Medical Corporation

\section{Stephen H. Thomas}

Hamad Medical Corporation

\section{Tim Harris}

Hamad Medical Corporation

\section{Ashfaq Shuaib}

University of Alberta

\section{Peter A. Cameron}

The Alfred Hospital, Monash University

\section{Maaret Castren}

Helsinki University Hospital and University of Helsinki

\section{Research Article}

Keywords: Act FAST, Public Campaign, Mass Media, Stroke Campaign, Stroke Awareness, EMS Activation, Qatar.

Posted Date: August 30th, 2021

DOI: https://doi.org/10.21203/rs.3.rs-798434/v1

License: (c) (i) This work is licensed under a Creative Commons Attribution 4.0 International License.

Read Full License 


\section{Abstract \\ Background}

Evaluation of public education stroke campaigns and behavioral studies to assess emergency response at stroke onset are scarce. We aimed to assess patient's and bystanders' foreknowledge of stroke signs and symptoms and their response at stroke onset. We also enquired if 'Act FAST' stroke campaign in Qatar contributed to their foreknowledge.

\section{Methods}

In Qatar, the first national stroke awareness campaign, 'Act FAST', was launched in May 2015. The study population included a convenience sample of stroke patients admitted to the stroke service in Qatar's largest tertiary care hospital from November 2015-February 2016. We interviewed patients with acute onset stroke admitted to the stroke unit using a validated questionnaire. If the patient had disabling stroke, we interviewed relatives/bystanders present at stroke onset. The primary outcome was the correct response of calling Emergency Medical Services (EMS), recognizing the possibility of stroke.

\section{Results}

The questionnaire was administered to 165 participants, $142(86.1 \%)$ stroke patients, and $23(13.9 \%)$ bystanders. The mean age of the study population was $52.6(\mathrm{SD}=11.7)$, and sex (male-female) ratio was 7:1. Ethnic categories were South-Asian $(n=101,62.2 \%)$, Middle-Eastern $(n=14,8.5 \%)$, Far-Eastern $(n=$ $26,15.8 \%)$, African $(n=16,9.7 \%)$ and Others $(n=8,4.9 \%)$. From the study group, $33(20.1 \%)$ participants had foreknowledge of stroke signs and symptoms, and of these, 27 (16.5\%) knew about the Act FAST campaign in Qatar. The behavioral responses of the participants (total $n=165$ ) on stroke onset included; immediately activated EMS $(n=55,33.3 \%)$, called friends/relatives $(n=69,41.8 \%)$, drove to hospital $(n=$ $33,20 \%)$, decided to rest and waited for improvement in condition $(n=21,12.7 \%)$, and $12(7.3 \%)$ responded as none of the above. Of the participants who admitted having watched the Act FAST campaign, $92.6 \%(25 / 27)$ reported that the campaign affected their response to stroke onset. There was no association of ethnicity, marital status or FAST campaign awareness with behavioral response of EMS activation on stroke onset.

\section{Conclusions}

The foreknowledge of stroke signs and symptoms and the Act FAST campaign was low in the community. However, seeking help by activating EMS at stroke onset was generally high in the study population irrespective of the awareness to the campaign. 


\section{Background:}

Stroke is a major cause of morbidity and the second leading cause of mortality worldwide (1-5). According to the WHO (World Health Organization) Global Burden of Disease data and the leading cause of deaths report, 6.1 million deaths were recorded due to stroke in $2019(4,6-8)$. The incidence of stroke is increasing in developing countries along with the prevalence of hypertension and diabetes. Qatar's population and age at stroke presentation in Qatar are younger than those in European and North American countries $(9,10)$. The indigenous population has undergone significant changes such as urbanization, increasing tobacco consumption, dietary changes, and sedentary lifestyle, contributing to an increased prevalence of vascular diseases (11-14). The incidence of stroke in Qatar is relatively high compared to European and North American countries $(10,12,15)$. The management of acute stroke is time-dependent so early recognition of the symptoms and rapid transfer to the hospital may reduce subsequent disability and mortality $(16,17)$.

Mass media campaigns are conducted globally focusing on improving community awareness about stroke signs and symptoms. The 'Act FAST' (Face drooping, Arm weakness, Speech problem, time is ticking) stroke campaign is one of the major internationally established stroke awareness programs. Studies conducted to assess its effectiveness and outcomes have reported variable success rates (1824). In the UK (United Kingdom), the campaign was found to be effective in creating an impact on stroke awareness and recognition, and in reducing pre-hospital delays in stroke patients $(21,25)$. Studies from Australia also demonstrated an increase in emergency calls and ambulance dispatches for stroke post campaign; however, they were not able to provide evidence of whether the calls were true stroke and transient ischemic attacks, or other stroke mimics $(20,22,23)$.

The cultural and linguistic diversity of Qatar's population presents particular challenges in the development of public health campaigns. The first 'Act FAST' national stroke awareness campaign was launched in May 2015 in Qatar (26). The campaign ran on television, newspaper, social media and billboard advertisements in multiple languages targeting the general population. There is no published study assessing the effectiveness and impact of this campaign in a diverse population like Qatar to inform future development.

The aim of this study was to assess the foreknowledge of patients and bystanders, of stroke signs and symptoms and their response at the stroke onset. A secondary objective was to determine if the 'Act FAST' stroke campaign in Qatar contributed to their foreknowledge.

\section{Methods:}

This was a prospective study conducted in the only tertiary care hospital in Qatar. The study was reviewed and approved by the Medical Research Center (MRC) and the Institutional Review Board (IRB) of Hamad Medical Corporation (MRC/0765/2015).

\section{Setting and study population}


Qatar is one of the six Middle Eastern GCC (Gulf Cooperation Council) countries located on the Arabian Peninsula's northeastern coast. Qatar has an ethnically diverse population of approximately 2.7 million, with about $88 \%$ being short-term immigrants from a wide range of countries (27-29). The local Qatari population constitutes only around $12 \% \%$ of the total, while South-East Asians (approx. $60 \%$ ), Non-Qatari Arabs (approx. 13\%), people from the Far-East (approx. 10\%) and minority groups from various other countries (approx. 5\%) form the major part of this society (27-30). Despite Arabic being the official language of Qatar and English being widely spoken, more than $65 \%$ of the non-Qatari population does not speak Arabic or English. In addition, the majority of this population were manual workers with limited education (31).

All stroke patients admitted to the stroke unit at Hamad General Hospital (HGH) between November 2015 till February 2016 were screened for participation utilizing the stroke team daily admissions log. Eligible participants ( $n=165$ ) were adults ( $\geq 18$ years) with neuro-imaging confirmed stroke, as assessed by the neurology team. Patient relatives or witnesses/bystanders who were present at the onset of the event were interviewed if the patient had a disabling stroke which prevented self-reporting. Excluded participants were $<18$ years old, clinically unstable and/or unfit for interview without a witness/bystander, unable to understand verbal communication and/or diagnosis other than the stroke.

\section{Data collection}

A validated questionnaire was the primary data collection tool and was modified to our local setting and population (appendix 1) (32). The questionnaire focused on the knowledge and awareness of 'Act FAST' stroke campaign in Qatar, stroke signs and symptoms and patient response at stroke onset to assess campaign penetration and perception of general population to acute stroke. The participants were approached within 48 hours of admission to the stroke unit and were screened for eligibility. Verbal consent was obtained from all eligible participants and a structured interview conducted in English or Arabic language by trained research team members. If the participant did not speak conversational English or Arabic a trained organizational approved translator was utilized. The response of each participant was recorded verbatim during the interview.

\section{Variables and data points}

The study questionnaire contained closed ended questions with pre-defined options and open-ended questions recording verbatim statements describing the FAST campaign, signs and symptoms of stroke and participants behavior at stroke onset. The closed ended questions included: awareness of stroke campaigns, awareness of the Act FAST stroke campaign in Qatar, knowledge of the signs and symptoms of stroke as depicted in the stroke campaign, the most common effective mediums used for the awareness campaigns, severity of different symptoms at stroke onset, behavioral response at symptom onset (with and without stroke recognition) and a conclusive analysis of how effective the awareness campaign was and how much it effected patients behavioral response at the onset of stroke symptoms (Appendix 1). 
The participant's understanding of the Act FAST campaign acronym was defined as satisfactory if the participants were able to identify three or more components of the 'FAST' acronym. Similarly, the participants' knowledge and awareness of stroke signs and symptoms was defined as satisfactory if the participant was able to describe two or more signs and symptoms included in the Act FAS' campaign. The effect of the campaign on evoking an appropriate behavioral response at the onset of symptoms was defined as the immediate activation of the emergency medical services (EMS).

\section{Outcome measures}

The primary endpoint of the study was the knowledge and awareness of the stroke awareness and Act FAST campaign in Qatar. Secondary endpoints were association of demographics and patient characteristics with stroke knowledge and awareness and EMS activation at stroke onset.

\section{Statistical analysis}

The descriptive analysis was reported as mean and standard deviation (SD) for all parametric continuous variables. All categorical variables were reported as numbers and percentages $(n, \%)$. We compared the proportion of all categorical data for sex, nationality, level of education, occupation, symptoms at stroke onset and behavioral response using Pearsons Chi-square test or Fisher exact test as appropriate. We also made comparisons using student's t test (means), with a $p$ value of $<0.05$ considered as statistically significant. All statistical analysis was conducted using STATA (quad-core 15MP, StataCorp, College Station, TX).

\section{Results:}

The questionnaire was administered to 165 participants, 142 (86.1\%) stroke patients and 23 (13.9\%) stroke bystanders (where the patient was unable to communicate). The mean age of our study population was $52.6(S D=11.7)$ years, and sex (male-female) ratio of 7:1. The Ethnic mix of the population was South Asian ( $n=101,62.2 \%)$, Far Eastern $(n=26,15.8 \%)$, African $(n=16,9.7 \%)$, Middle Eastern $(n=14,8.5 \%)$, and Others $(n=8,4.9 \%)$. Graduate level education was reported in $66(40 \%)$ of the participants while the remainder of the participants were either primary level $8(4.9 \%)$, secondary level 27 (16.5\%), high school level $54(32.9 \%)$ or uneducated $9(5.5 \%)$.

Among those interviewed, 33 (20.1\%) participants knew about the signs and symptoms of stroke. 27 (16.5\%) participants were aware of the 'Act FAST' stroke awareness campaign and 7 (4.8\%) were able to recall the campaign acronyms and the message conveyed by the campaign. The behavioral responses of the study participants who were aware of the Act FAST campaign at the onset of stroke signs and symptoms were; 13 (48.2\%) participants called relatives/friends, 13 (48.2\%) of the participants immediately activated EMS, and $3(11.1 \%)$ drove to the hospital. Unilateral limb weakness $(n=19,17.4 \%)$ was the most commonly reported motor symptom among participants who were aware of the Act FAST campaign, followed by numbness, difficulty in talking, dizziness, drooping of face, headache, loss of balance, and blurred vision (Table 1). 
Page $6 / 15$ 
Table 1

Comparison of demographics of the population and its effect in knowledge perception of ACT FAST

\begin{tabular}{|c|c|c|c|}
\hline \multirow[t]{2}{*}{ Variable } & \multicolumn{2}{|c|}{ Act FAST Awareness } & \multirow[t]{2}{*}{ p-value } \\
\hline & Yes $(n=27)$ & No $(n=138)$ & \\
\hline Age, year, mean (SD) & $54.7(13.2)$ & $52.18(11.4)$ & 0.31 \\
\hline Gender Male & $21(77.8)$ & $123(89.1)$ & 0.11 \\
\hline Female & $6(22.2)$ & 15 (10.9) & 0.11 \\
\hline \multicolumn{4}{|l|}{ Ethnicity } \\
\hline South Asian & $13(48.2)$ & $88(63.8)$ & \\
\hline Middle Eastern & $5(18.5)$ & $9(6.5)$ & \\
\hline Far Eastern & $3(11.1)$ & $23(16.7)$ & \\
\hline African & $3(11.1)$ & $13(9.4)$ & \\
\hline Other & $3(11.1)$ & $5(3.6)$ & \\
\hline \multicolumn{4}{|l|}{ Marital } \\
\hline Married & $23(85.2)$ & $125(90.6)$ & 0.399 \\
\hline Unmarried & $4(14.8)$ & $13(9.4)$ & \\
\hline \multicolumn{4}{|l|}{ Education } \\
\hline Primary & $0(0)$ & $8(5.8)$ & \\
\hline Secondary & $1(3.8)$ & $26(18.8)$ & \\
\hline High School & $8(30.7)$ & $46(33.3)$ & \\
\hline Graduated & $16(61.5)$ & $50(36.2)$ & \\
\hline Other & $1(3.8)$ & $8(5.8)$ & \\
\hline \multicolumn{4}{|l|}{ Response } \\
\hline Drove to hospital & $3(11.1)$ & $30(21.7)$ & \\
\hline Call friends/relative & $13(48.2)$ & $56(40.6)$ & \\
\hline Call EMS & $13(48.2)$ & $42(30.4)$ & \\
\hline Wait to improve & $0(0)$ & $17(12.3)$ & \\
\hline Rest & $1(3.7)$ & $3(2.2)$ & \\
\hline Other & $2(7.4)$ & $10(7.2)$ & \\
\hline
\end{tabular}




\begin{tabular}{|llll|}
\hline Variable & \multicolumn{2}{l}{ Act FAST Awareness } & p-value \\
\hline Bystander & $10(37.1)$ & $13(9.4)$ & $<0.01$ \\
\hline First symptom noticed & & \\
Weakness of limbs & $19(70.4)$ & $83(60.6)$ & \\
Drooping of face & $4(14.8)$ & $8(5.8)$ & \\
Numbness & $7(25.9)$ & $13(9.5)$ & \\
Difficulty in talking & $6(22.2)$ & $31(22.6)$ \\
Dizziness & $5(18.5)$ & $31(22.6)$ \\
Loss of balance & $3(11.1)$ & $7(5.1)$ & \\
Blurred vision & $2(7.4)$ & $3(2.2)$ \\
Headache & $4(14.8)$ & $12(8.8)$ \\
Difficulty swallowing & $0(0)$ & $1(0.7)$ \\
I don't remember & $0(0)$ & $1(0.7)$ \\
\hline
\end{tabular}

Twenty-one $(14.5 \%)$ of the $(n=144)$ male participants were aware of the Act FAST stroke awareness campaign as compared to $6(28.5 \%)$ of the 21 female participants reported to know about the campaign before having stroke symptoms. The majority of the participants from campaign aware group had a graduation level (16 out of $27,59.3 \%)$ education; whereas, $36.2 \%(n=50)$ of the participants from campaign unaware group had a graduate level education. A significant proportion of the participants who were aware of the campaign were witnesses/bystanders 10 (37.1\%).

The participants from the campaign aware group compared to the campaign unaware group who responded by activating EMS were $13(48.2 \%)$ and 42 (30.4\%) respectively. Seeking help by only calling friends or relatives was reported by $8(29.6 \%)$ from aware group compared to $41(29.7 \%)$. The participants from the campaign aware group compared to the campaign unaware group who did not seek any help and waited to see if the symptoms resolved were $3(11.1 \%)$ and $26(18.8 \%)$ respectively.

The most significant campaign awareness among the participants stemmed from paper-based advertising. The majority of the participants acquired stroke campaign knowledge from billboards 19 (11.52\%), hospitals $4(2.4 \%)$, poster/leaflets $4(2.4 \%)$, workplace $3(1.8 \%)$, posters at malls/cinemas 2 (1.2\%).

Electronic based advertising was less successful among the participants (television 9 (5.45\%), internet 3 $(1.8 \%)$, radio $3(1.8 \%)$ ) and social media the least successful (Facebook, Twitter, YouTube) reaching only $2(1.2 \%)$. 


\section{Discussion:}

In this study foreknowledge of stroke signs and symptoms, and awareness about the Act FAST campaign was lower than expected. Although the campaign ran through multiple communication mediums throughout Qatar, awareness of the Act FAST campaign was low (16.5\%). Most participants (>50\%) belonged to the less educated craft and manual workers, who have limited communication skills in English and Arabic languages, and many lack access to commercial media running the Act FAST campaign (31).

Several studies have been conducted to assess the effect of mass media stroke campaigns on the behavioral response of the targeted population, aiming to improve patient outcomes (18-24). A similar campaign in the UK was found highly effective in creating impact on stroke awareness and recognition; however, it had little impact on the behavioral response to stroke symptoms (21). Our data suggest, even though the public awareness to the campaign was lower [27 out of $165(16.5 \%)$ ] compared to the UK study [68 out of $75(90.6 \%)$ ]; $55(33.3 \%)$ of our study population activated EMS at stroke onset which is comparable to the participants activating EMS 28 (37.3\%) in the UK. Our study suggests that apart from knowledge and awareness the behavioral response at stroke onset is multifactorial, and may vary from person to person.

Another study suggested that the UK 'Act FAST' campaign successfully reduced pre-hospital delays in stroke patients and also significantly increased the percentage of bystanders seeking medical attention after identifying signs and symptoms of stroke (25). Our data supports this evidence, considering $43.5 \%$ (10 out of 23) of the bystanders in the study group were aware of the stroke 'Act FAST campaign', and 7 of $10(70 \%)$ bystanders from aware group sought medical attention by activating the emergency services.

Since media has become a significant source of providing information to the general population, the clarity and impact of mass media interventions in changing behavioral responses requires careful evaluation $(33,34)$. Studies in Australia have concluded that the ambulance dispatches for stroke as well as the awareness of the general population for stroke warning signs significantly increased following their 'Act FAST' stroke awareness campaign. The studies also suggested the campaigns were more effective in increasing the ambulance dispatches when the knowledge of FAST symptoms was linked to calling an ambulance at symptom onset $(22,23)$.

The Act FAST stroke campaign in Qatar focused on disseminating stroke awareness using pictorial representations of FAST components with strong emphasis on calling EMS immediately (Fig. 1). The education level of the target population and language of communication used for the campaign has a significant role in message penetration among the general population. Most participants in our study were non-native speakers of Arabic or English. However, the Qatar Act FAST campaign was mainly conducted in English and Arabic languages, which may be one of the reasons for lower success rates. We believe education level of the population, language of mass media communication, and the access to channels of advertisements were unmeasured factors which could explain the difference observed between our study results and the results reported from Australian and the UK campaigns. Further studies 
focused on factors mentioned above will inform public strategies focused to reduce pre-hospital delays and to improve outcomes for stroke patients using the 'Act FAST' campaign in Qatar.

Although, our study describes the perception, awareness and response evoked by the campaign among the target population including bystanders, there are some limitations to our study. Firstly, we were unable to record the language read and understood by the participants. Considering the majority of our population are expatriates, language barriers could play an important role in the understanding of this public health intervention. Secondly, we had a limited sample of participants, with the majority of the participants belonging to the South-Asian region. Thirdly, although the study interview was conducted within 48 hours of admission to the stroke unit and by survey trained stroke team members, the study relied on the recall of the participants. Fourthly, the study was executed after the second wave of the Act FAST stroke awareness campaign and perception of the campaign and the response based on recall of the campaign may have changed for participants interviewed later in the study. Finally, the type of stroke was not defined for participants in our study and included all stroke patients admitted to the stroke unit. However, our study is one of the first studies in Qatar to conduct detailed interview of stroke patients including bystanders after a national stroke awareness campaign.

\section{Conclusions:}

The awareness and knowledge of stroke presentations following the stroke 'Act FAST' campaign in patients with a confirmed stroke and their bystanders was low in the study population. However, seeking help by activating Emergency Medical Services at stroke onset was generally high in the study population.

\section{List Of Abbreviations}

\section{EMS}

Emergency Medical Services

FAST

Face, Arm, Speech, Time

GBD

Global Burden of Disease

GCC

Gulf Cooperation Council

IRB

Institutional Review Board

MRC

Medical Research Center

SD

Standard Deviation

UK 
United Kingdom

WHO

World Health Organization

\section{Declarations}

Ethics approval and consent to participate: This study was reviewed and was granted approval by the Institutional Review Board (IRB) and the Medical Research Center (MRC) at Hamad Medical Corporation (HMC), Doha, Qatar (Reference number: MRC/0765/2015; Protocol number: 15238/15). A verbal consent for participation was obtained from all participants prior to the interview. The study was conducted in accordance with all institutional and relevant guidelines and regulations.

Consent for publication: Not applicable

Availability of data and materials: The data that support the findings of this study are available from Hamad Medical Corporation but restrictions apply to the availability of these data, which were used under license for the current study, and so are not publicly available. Data is however available from the authors upon reasonable request and with permission of Hamad Medical Corporation.

Competing interests: The authors declare that they have no competing interests.

Funding: The research project was supported by the Health Service Research Investigator Initiated Grant (HSRIIG) cycle by the Medical Research Center at Hamad Medical Corporation, Doha, Qatar. There was no role of the study sponsor/funder, if any, in the study conception, study design, data collection, data analysis and interpretation of data, manuscript writing and the decision to publish the manuscript.

T.P.: Finska Läkaresällskapet (T.P.), Viipurin tuberkuloosisäätiö (T.P.), Maire Taposen säätiö (T.P.)

\section{Authors' contributions:}

Z.B. conceived the study proposal, compiled, and modified the data collection tool to local setting and population, data collection and data management, data cleaning and analysis, data interpretation, abstract and manuscript writing.

S.P. conceptualized the proposal with Z.B. and reviewed proposal, review and modification of the data collection tool, data analysis and interpretation, abstract and manuscript writing.

T.P., M.C. and P.C. reviewed the data, conducted review of the data analysis and interpretation of results, writing and review of the manuscript and provided overall supervision for the study.

N.A. supported in the designing of the data collection process, conducted review of the data and writing and review of the manuscript. 
S.T. supported in the conceptualizing of the study proposal, data interpretation and review of the manuscript.

T.H. reviewed the data, conducted review of data analysis and interpretation of results, writing and review of the manuscript and provided overall supervision for the study.

A.S. conceptualized the stroke campaign and review of the manuscript.

Acknowledgements: We are truly grateful and would like to thank Dr. Furqan B. Irfan (MBBS, PhD, MBA, Assistant Professor, Director Research Development, Michigan State University) for his efforts and contribution in the grant proposal for this study. We would also like to thank Ms. Paula Jayne Bourke, Ms. Sujatha Joseph and Mr. Mark Santos from the Department of Neurology, Hamad General Hospital, Hamad Medical Corporation for their contribution and support in the execution and progress of the study on site.

\section{References}

1. Wasay M, Khatri IA, Kaul S. Stroke in South Asian countries. Nat Rev Neurol. 2014;10(3):135-43.

2. Johnston SC, Mendis S, Mathers CD. Global variation in stroke burden and mortality: estimates from monitoring, surveillance, and modelling. Lancet Neurol. 2009;8(4):345-54.

3. Feigin VL, Nguyen G, Cercy K, Johnson CO, Alam T, Parmar PG, et al. Global, Regional, and CountrySpecific Lifetime Risks of Stroke, 1990 and 2016. N Engl J Med. 2018;379(25):2429-37.

4. World Health Organization: The top 10 causes of death. Fact sheets. 2020: (https://www.who.int/news-room/fact-sheets/detail/the-top-10-causes-of-death).

5. The World Health Report 2003: Shaping the future. Geneva. World Health Organization. 2003,https://www.who.int/whr/2003/en/.

6. Gorelick PB. The global burden of stroke: persistent and disabling. Lancet Neurol. 2019;18(5):417-8.

7. Johnson CO, Nguyen M, Roth GA, Nichols E, Alam T, Abate D, et al. Global, regional, and national burden of stroke, 1990-2013;2016: a systematic analysis for the Global Burden of Disease Study 2016. The Lancet Neurology. 2019;18(5):439-58.

8. Lanas F, Seron P. Facing the stroke burden worldwide. The Lancet Global Health. 2021;9(3):e235-e6.

9. Rukn SA, Mazya MV, Hentati F, Sassi SB, Nabli F, Said Z, et al. Stroke in the Middle-East and North Africa: A 2-year prospective observational study of stroke characteristics in the region-Results from the Safe Implementation of Treatments in Stroke (SITS)-Middle-East and North African (MENA). Int J Stroke. 2019:1747493019830331.

10. Akhtar N, Kamran S, Singh R, Malik RA, Deleu D, Bourke PJ, et al. The Impact of Diabetes on Outcomes After Acute Ischemic Stroke: A Prospective Observational Study. J Stroke Cerebrovasc Dis. 2019;28(3):619-26. 
11. Ibrahim F, Deleu D, Akhtar N, Al-Yazeedi W, Mesraoua B, Kamran S, et al. Burden of Stroke in Qatar. J Stroke Cerebrovasc Dis. 2015;24(12):2875-9.

12. Behrouz R, Powers CJ. Epidemiology of classical risk factors in stroke patients in the Middle East. Eur J Neurol. 2016;23(2):262-9.

13. Jaam M, Al-Marridi W, Fares H, Izham M, Kheir N, Awaisu A. Perception and intentions to quit among waterpipe smokers in Qatar: a cross-sectional survey. Public Health Action. 2016;6(1):38-43.

14. Al-Thani M, Al-Thani AA, Al-Mahdi N, Al-Kareem H, Barakat D, Al-Chetachi W, et al. An Overview of Food Patterns and Diet Quality in Qatar: Findings from the National Household Income Expenditure Survey. Cureus. 2017;9(5):e1249.

15. Ali FM, Nikoloski Z, Reka H, Gjebrea O, Mossialos E. The diabetes-obesity-hypertension nexus in Qatar: evidence from the World Health Survey. Popul Health Metr. 2014;12:18.

16. Gradison M. Decreasing the morbidity, mortality, and cost of stroke through awareness and prevention. Am Fam Physician. 2003;68(12):2335, 9-40.

17. Berg EG. Brain drain. Spotting a stroke fast can prevent damage. Diabetes Forecast. 2013;66(9):323.

18. Dombrowski SU, White M, Mackintosh JE, Gellert P, Araujo-Soares V, Thomson RG, et al. The stroke 'Act FAST' campaign: remembered but not understood? Int J Stroke. 2015;10(3):324-30.

19. Mellon L, Hickey A, Doyle F, Dolan E, Williams D. Can a media campaign change health service use in a population with stroke symptoms? Examination of the first Irish stroke awareness campaign. Emerg Med J. 2014;31(7):536-40.

20. Bray JE, Straney L, Barger B, Finn J. Effect of public awareness campaigns on calls to ambulance across Australia. Stroke. 2015;46(5):1377-80.

21. Dombrowski SU, Mackintosh JE, Sniehotta FF, Araujo-Soares V, Rodgers $H$, Thomson RG, et al. The impact of the UK 'Act FAST' stroke awareness campaign: content analysis of patients, witness and primary care clinicians' perceptions. BMC Public Health. 2013;13:915.

22. Bray JE, Johnson R, Trobbiani K, Mosley I, Lalor E, Cadilhac D. Australian public's awareness of stroke warning signs improves after national multimedia campaigns. Stroke. 2013;44(12):3540-3.

23. Bray JE, Mosley I, Bailey M, Barger B, Bladin C. Stroke public awareness campaigns have increased ambulance dispatches for stroke in Melbourne, Australia. Stroke. 2011;42(8):2154-7.

24. Flynn D, Ford GA, Rodgers H, Price C, Steen N, Thomson RG. A time series evaluation of the FAST National Stroke Awareness Campaign in England. PloS one. 2014;9(8):e104289.

25. Wolters FJ, Paul NL, Li L, Rothwell PM. Sustained impact of UK FAST-test public education on response to stroke: a population-based time-series study. Int J Stroke. 2015;10(7):1108-14.

26. HMC. Hamad Medical Corporation launches stroke awareness campaign. Marhaba 2015.

27. Akhtar N, Salam A, Kamran S, Bourke P, Joseph S, Santos M, et al. Ethnic variation in acute cerebrovascular disease: Analysis from the Qatar stroke registry. Eur Stroke J. 2016;1(3):231-41. 
28. Hillman S, Ocampo Eibenschutz E. English, super-diversity, and identity in the State of Qatar. World Englishes. 2018;37(2):228-47.

29. Planning and statistics authority: Monthly figures on total population. https://wwwpsagovqa/en/statistics1/StatisticsSite/pages/populationaspx. 2021.

30. Qatar population 2019. World population review. 2019; http://worldpopulationreview.com/countries/qatar.

31. Ahmad R, Hillman S. Laboring to communicate: Use of migrant languages in COVID-19 awareness campaign in Qatar. Multilingua. 2020.

32. Bray JE, O'Connell B, Gilligan A, Livingston PM, Bladin C. Is FAST stroke smart? Do the content and language used in awareness campaigns describe the experience of stroke symptoms? Int J Stroke. 2010;5(6):440-6.

33. Muller-Nordhorn J, Nolte CH, Rossnagel K, Jungehulsing GJ, Reich A, Roll S, et al. Knowledge about risk factors for stroke: a population-based survey with 28,090 participants. Stroke. 2006;37(4):94650 .

34. Li S, Cui L-Y, Anderson C, Zhu S, Xu P, Wei T, et al. Public Awareness of Stroke and the Appropriate Responses in China. Stroke. 2019;50(2):455-62.

\section{Figures}



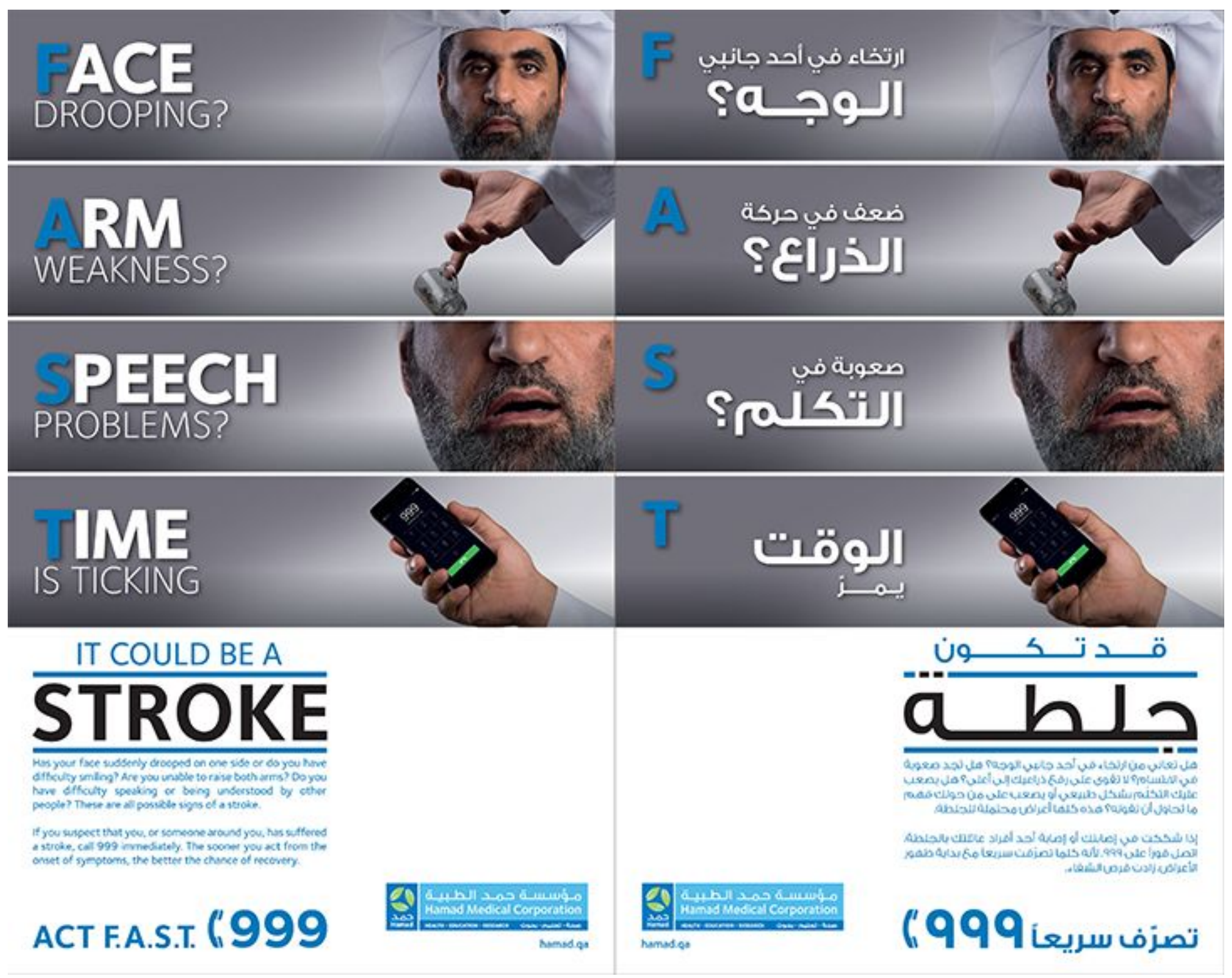

\section{Figure 1}

The ACT FAST advertisement from the National Stroke Awareness Campaign in Qatar in 2015. Legend: Access figure: https://www.hamad.qa/EN/news/2015/May/Pages/Hamad-Medical-CorporationLaunches-Stroke-Awareness-Campaign.aspx

\section{Supplementary Files}

This is a list of supplementary files associated with this preprint. Click to download.

- Supplementaryfile.docx

- Appendix1.pdf 